\title{
Language habits and detection in very short-term memory*:
}

\author{
D. J. HERRMANN $\dagger$ and JOHN P. McLAUGHLIN \\ University of Delaware, Newark, Delaware 19711
}

\begin{abstract}
Target letters in briefly presented word displays are known to be better detected than when they are presented in anagram arrangements of the words' letters. Target detection may have been higher for word displays either because Ss identified the words and then determined if a word possessed the target or because, in word displays, $\$$ s could anticipate letters from the transitional probabilities (TRP) of letters in the language (TRP hypothesis). Detection in Experiment I was identical for words and for pseudowords, stimuli which were meaningless rearrangements of the words' letters but which presented the words' level of interletter TRP. Randomly rearranged displays, with lower TRP values, yielded lower detection rates. Experiment II showed that detection increased with TRP levels in nonword displays. The results support the TRP hypothesis and thus are consistent with a serial-scanning process in very short-term memory, but are also consistent with a special variant of a parallel process.
\end{abstract}

It has been shown that the processing of lettered displays from very short-term memory (Estes, 1972) is a function of the contents of the display. McIntyre, Fox, and Neale (1971) found that the detection of one of two possible critical letters (targets) in a matrix of 14 letters depended on redundancy among nontarget letters. Detection was more accurate when the background letters were redundant, e.g., all Os, than when background letters were different from each other. This result was extended by McLaughlin, Masterson, and Herrman (1972), who found that detection increased systematically as backgrounds were varied from non- to semi- to total redundancy.

McIntyre et al suggested that common features of the whole array were processed simultaneously, i.e., that matrix cells are scanned in parallel. On the other hand, McLaughlin et al showed that a cell-by-cell, serial model could account for the phenomenon, if a serial model assumes that the speed of processing a cell is dependent on the previous history of processing letters from the matrix. If the letter currently being processed is different from previous letters scanned, more time is needed for processing than if the letter is the same as previous letters scanned. Thus, if $S$ has processed the letter $\mathrm{H}$ in a display, he may be predisposed to expect another $\mathrm{H}$ in the display. If a subsequent letter is an $\mathrm{H}$, processing is faster than if some other letter is encountered which was not scanned earlier in the display.

If detection of a critical letter in a matrix involves a serial process which depends on varying expectancy (cf. Aderman \& Smith, 1971), then detection might be affected by the expectancies involved in one's language habits. Serial processing of letters might be faster and thus render detection more accurate in a matrix with

\footnotetext{
*The authors thank Edward E. Smith for helpful comments on an earlier draft of the article. Reprint requests may be sent to John P. McLaughlin, Department of Psychology, University of Delaware, Newark, Delaware 19711.

†Now at the Department of Psychology, Stanford University, Stanford, California 94305.
}

letter sequences that are similar to those in the language than it will be in a matrix with a random arrangement of letters. For example, S might process the sequence "th" faster than "tz." This would be because $S$ can anticipate that the letter $h$ is very likely to follow the letter $t$ in text, whereas he is less likely to expect that a $z$ will follow $t$.

Evidence supporting the predictions of an expectancy model of serial processing was provided by the results of Reicher (1969) (cf. Wheeler, 1971). Reicher found that target-letter detection was more accurate in a display containing one or two four-letter words than in a display containing one or two anagram arrangements of the words. These results suggest that cell-by-cell processing is swifter when content is predictable by the transitional probabilities (TRP) of letters in the language than when content is not predictable.

An alternative explanation of Reicher's results, however, is possible. In his experiment, eight out of nine Ss were aware of words being in displays. As Reicher noted, it is conceivable that an expectancy for letter-to-letter sequences was not operating in his Ss. An $\mathrm{S}$ may have identified a display as a word and later determined if that word possessed the target, rather than actually sampling cell-by-cell for the target. In other words, the $S$ was set to identify the rows of a display by comparing a row to four-letter words in memory. Reicher's anagram arrangements were not words, i.e., they were meaningless, and therefore could not have been processed in this way.

Reicher's design did not permit a choice between the alternative explanations of his results, because his anagram stimuli were not only meaningless but also were letter sequences which did not reflect language patterns. Had he presented pseudoword displays, i.e., letter sequences which were meaningless but which reflected the sequential dependencies in the language, as well as word displays and anagram displays, a choice between the explanations would have been possible. If the word-identification hypothesis accounted for Reicher's data, then detection for pseudoword displays would not 
have been higher than that for the anagram displays. Conversely, if expectancy operated on the probability of let ter-to-letter transitions (TRP hypothesis), detection of pseudoword displays would have been as accurate as word displays. The purpose of Experiment I was to examine these alternative explanations by investigating detection accuracy for displays containing words, pseudowords, and random-letter displays.

\section{EXPERIMENT I}

\section{Method}

\section{Subjects}

Three male and six female undergraduates from the University of Delaware volunteered for participation. All Ss had normal or corrected visual acuity.

\section{Apparatus}

Stimuli were presented in a three-channel tachistoscope (Scientific Prototype Model GB). A white adaptation field was presented continuously, except during presentation of stimulus matrices. The intensity of all stimuli and the adaptation field was $2.1 \mathrm{fc}$. measured at the eye. Stimulus duration was $25 \mathrm{msec}$.

Stimuli were displays of 16 letters printed in a 4 by 4 matrix. Letters were black 36-point Futura Medium decals and were fixed on white cards. A matrix diagonal subtended a 3-deg 32-min visual angle.

\section{Procedure}

Ten matrices represented each of three conditions. A matrix in the word condition consisted of four words, each four letters long, arranged one above the other in the rows of a matrix. No two words in the matrix began with the same first letter. All words in a matrix were of the same frequency in the Howes count of spoken English (1966). Five matrices contained a B, and five contained an F. Across the 10 matrices, 9 out of the 16 cells contained a critical letter. These 9 cells were distributed approximately evenly across the top and bottom and left and right sides of the matrices.

Each of the 10 matrices in the pseudoword condition was yoked to one of the matrices in the word condition. A pseudoword matrix contained the same letters represented in its mate in the word condition. These letters were rearranged to resemble words, with the restriction that the target retain the position it had in the word matrix.

Each of the 10 matrices in the random condition was also yoked to one of the matrices in the word condition. A random matrix also contained the same letters represented in its mate in the word condition. These letters were positioned randomly in the matrix, with the exception of the target, which kept the same position it had held in the word matrix. Transitional probability (TRP) between individual letters, from left to right, was estimated for the three conditions by the bigram frequencies in 15,000 words of running English text reported by Underwood and Schulz (1960). The mean bigram frequencies on a row was 301 for the word matrices, 286 for pseudoword matrices, and 148 for the random matrices.

Ss were seated at the viewing aperture of the tachistoscope with their heads supported in a Bausch and Lomb chinrest, and light-adapted for $5 \mathrm{~min}$ while receiving the experimental instructions. They were told that either $B$ or $F$ would be present in each stimulus matrix, and were instructed to guess which critical target was present on each trial. In all, 30 matrices were presented to each $S$. For a given trial, $S$ was told when a stimulus was available for viewing and was then able to trigger the presentation himself.

\section{Results and Discussion}

Mean correct detection was $78.8 \%$ for the word matrices, $78.8 \%$ for the pseudoword matrices, and $63.4 \%$ for the random matrices. An analysis of variance confirmed that detection accuracy was poorer for the random matrices than for the word and pseudoword matrices, $F(2,16)=5.14, p<.05$.

The word and pseudoword matrices clearly resulted in more accurate detection than did the randomly arranged matrices. The virtually equivalent detection rates for word and pseudoword matrices indicate that the meaning in word matrices did not facilitate detection over that for the pseudoword matrices. Apparently, detection was facilitated by the higher row TRP in word and pseudoword displays relative to the random condition.

Six out of nine Ss reported after the experiment that they were unaware of the presence of words in any of the matrices. These Ss exhibited the same pattern of correct detection as the whole sample and as that reported by Reicher for the comparable conditions, i.e., targets were better detected in word matrices than in random matrices. Mean percent correct detection for these Ss was 77.7 for word displays and for pseudoword displays and 65.0 for random displays. This result is not consistent with the word-identification hypothesis. To pursue this support for the TRP hypothesis, Experiment II examined the relationship between row TRP and detection accuracy for displays which never contained word stimuli. Thus, any effects on detection could not be explained by the word-identification hypothesis.

\section{EXPERIMENT II}

\section{Method}

\section{Subjects}

Six male and seven female undergraduates from the University of Delaware volunteered for participation. All Ss had normal or corrected visual acuity.

\section{Apparatus}

The tachistoscope and physical parameters of the adaptation and stimulus fields were identical to those of the first experiment.

\section{Procedure}

Each of three conditions of row TRP were represented by 10 matrices. The physical characteristics of stimuli, e.g., visual angles, were identical to those of Experiment I. TRP between individual letters was again estimated by the bigram frequencies in 15,000 words of running English text reported by Underwood and Schulz (1960). Three levels of row interitem TRP were selected. Each high-TRP matrix was yoked to one matrix in the 
medium- and low-TRP conditions, The high-, medium-, and low-TRP matrices contained the same letters positioned in different cells, except for the target letter, which retained the same position.

Letters were arranged in the low-TRP matrices to have an average bigram frequency on a row of 21 ; medium-TRP matrices had a frequency of 256 , and high-TRP matrices had a frequency of 495. An additional restriction on the selection of letters for the 15 nontarget cells was that no letter could be used more than twice. As in the previous experiment, for the 10 matrices in each condition, half of the stimuli had $B$ and half had $F$ as the target item. All other aspects of the procedure were the same as in Experiment I.

\section{Results and Discussion}

Mean correct detection was $55.4 \%$ for the low-TRP matrices, $62.3 \%$ for the medium-TRP matrices, and $69.2 \%$ for the high-TRP matrices. An analysis of variance confirmed that detection rate increased with row TRP, $F(2,24)=3.68, p<.05$. Inspection of the frequency of errors as a function of the cell position of the critical element did not reveal differences in detection as a function of whether the target was in the top or bottom or the left or right side of the matrix.

The results of Experiment II support the TRP explanation of the results of Reicher (1969) and of the first experiment. TRP is a conditional probability, and, therefore, rests on a temporal relationship between events. In the present case, an event is the processing of a letter. The present data, consequently, provide strong evidence for a serial process in very short-term memory.

\section{GENERAL DISCUSSION}

One explanation of the effect of TRP appears to be based on a varying expectancy in the serial processing of a matrix. In addition to being consistent with the expectancy assumption of the model of McLaughlin et al (1972), the present data are consistent with nonmathematical theories of information processing. If processing of meaning is the comparison of a stimulus representation with a "dictionary" of symbols (cf. Norman, 1969), then speed of processing should increase with the efficiency of such comparisons. Efficiency should be enhanced by anticipation of the content of a cell. The conditions of word and pseudoword matrices in Experiment I and of high and medium TRP in Experiment II provide $\mathrm{S}$ with opportunities to anticipate the content of a given cell on the basis of the results of prior scanning. Successful anticipation would result in fewer comparisons for recognition, and thus more rapid processing. Since more cells could be processed before the image decayed, target detection would be enhanced.

It is somewhat paradoxical that TRP affected detection but that the position of the critical element did not affect detection. If Ss' scanning process was operating in the same manner as one reads English, i.e., from left to right and from top to bottom, then the greater proportion of errors should have been in displays with the target located in the right side and bottom of the matrix. To resolve this paradox, it must be assumed that Ss initiated their scan at a random position on a row in the matrix and then continued a left-to-right scanning process. Alternatively, the paradox may not exist. The 13 Ss each responded to only 30 displays. With so few displays, there were a small number of errors per position of targets in the matrix. Consequently, the data may have been insufficient to provide an adequate test of the relationship between target position and detection.

The present results contrast with the conclusions of Smith and Haviland (1972). They required Ss to detect Petters in displays of three-letter words (rag) and nonwords (rsg). The set of word stimuli nonwords were generated by the same rules, except that nonwords had a consonant, such as $s$, in the middle position of the three letters. Detection was higher for words than for nonwords, even when Ss were instructed and well practiced on the rules and letters used in generating word and nonword stimuli. Smith and Haviland concluded that the "inference" hypothesis, i.e., basing processing on letter predictability, was not supported since Ss did not process nonwords as well as words when Ss were aware of the statistical generation rules. However, it would seem to be literally impossible to provide sufficient practice at using their statistical generation rules which would be equivalent with the enormous amount of prelaboratory practice at using the TRP of letters in the language.

It must be noted that, in the present studies, TRP was perfectly confounded with pronounceability of stimuli. Low-TRP matrices were clearly less pronounceable than medium- and high-TRP matrices. Expectancy may operate on an acoustic level rather than on a visual level. This confound does not necessarily conflict with the present conclusion that effects from TRP are due to a serial process, since pronunciation involves a sequential formation of phonemes. Nevertheless, pronounceability may not be a problem at all, since Gibson, Shurcliff, and Yonas (1970) obtained an effect from orthographic structure even when Ss were congenitally deaf. Orthographic structure to Gibson et al is similar to TRP in being spelling regularities, including position rules, i.e., "pr" never occurs at the end of a word.

The effect of TRP does not point unequivocally to a serial process. Wheeler (1970) proposed a parallel model, in which the results of processing features in cell $\mathrm{n}$ might be used concurrently to direct the feature processing in cell $n+1$. TRP would have effects because spelling regularities limit the possibilities in adjacent cells. Thus, both a serial- and a parallel-process model can account for the effects of TRP. More intricate designs will be necessary to make a choice between the serial and parallel model.

\section{REFERENCES}

Aderman. D.. \& Smith. E. E. Expectancy as a determinant of 
functional units in perceptual recognition. Cognitive Psychology. 1971, 2. 117-129.

Estes, W. K. Interactions of signal and background variables in visual processing. Perception \& Psychophysics, 1972, 12, 278-286.

Gibson, E. J.. Shurcliff. A., \& Yonas, A. Utilization of spelling patterns by deaf and hearing subjects. In $H$. Levin and J. P. Williams (Eds.), Basic studies on reading. New York: Basic Books, 1970.

Howes, D. A word count of spoken English. Journal of Verbal Learning \& Verbal Behavior, 1966, 5, 572-604.

IIcIntyre, C., Fox, R., \& Neale, J. Effects of noise similarity and redundancy on the information processed from brief visual displays. Perception \& Psychophysics, 1970, 7, 328-332.

McLaughlin, J. P.. Masterson, F. A., \& Herrmann, D. J. Pattern redundancy and detection in very short-term memory. Perception \& Psychophysics, 1972, 12, 205-208.
Norman, D. A. Memory and attention: An introduction to human information processing. New York: Wiley, 1969.

Reicher, G. M. Perceptual recognition as a function of meaningfulness of stimulus material. Journal of Experimental Psychology, 1969, 81, 275-280.

Smith, E. E., \& Haviland, S. E. Why words are perceived more accurately than non-words: Inference versus unitization. Journal of Experimental Psychology, 1972, 92, 59-64.

Underwood, B. J., \& Schulz, R. W. Meaningfulness and verbal learning. Philadelphia: Lippincott, 1960.

Wheeler, D. D. Processes in word recognition. Cognitive Psychology, 1970, 1, 59-85.

(Received for publication July 31,1972 ; revision received June 26,1973 .) 